\title{
Presencia de anticuerpos IgG del virus de la rubéola, virus herpes simple y citomegalovirus en embarazadas residentes en Ciudad de La Habana
}

\author{
Carmen Acosta ', Xiomara Pérez ${ }^{1}$, Regla Herrera ${ }^{1}$, Raquel García ${ }^{2}$ \\ 1 Centro de Inmunoensayo, Ciudad de La Habana, Cuba. \\ 2 Policlínica 27 de noviembre, Ciudad de La Habana, Cuba.
}

\begin{abstract}
Se realizó un estudio seroepidemiológico con 207 gestantes, residentes en el municipio Marianao de Ciudad de la Habana, con la finalidad de conocer la presencia de anticuerpos IgG anti-rubéola, anti-citomegalovirus y anti-herpes simple (1 y 2); el nivel de positividad se expresó como la relación de la fluorescencia de la muestra con respecto a la del control positivo, para un nivel de corte de 0,3 para rubéola, 0,2 para citomegalovirus y 0,185 para herpes simple. Las seroconversiones se expresaron como el incremento de esta relación con respecto a la determinación realizada en el primer trimestre de embarazo. El 91,3\% de las gestantes resultaron positivas para rubéola, el $92,7 \%$ para citomegalovirus y el $98,1 \%$ para herpes simple. Se sugiere la valoración de aspectos fundamentales relacionados con estas infecciones dentro del Programa Nacional de Atención a las Embarazadas.
\end{abstract}

Palabras claves: rubéola, citomegalovirus, virus herpes simple, gestantes, Ciudad de La Habana.

Presence of IgG antibodies for rubella, herpes simplex and cytomegalovirus in pregnant women living in Havana City

A seroepidemiological study of 207 pregnant women living in Marianao, Havana City, was carried out to measure rubella, cytomegalovirus and herpes simplex anti-lgG antibodies. The cutoff level was established as the ratio between the sample's fluorescence and the positive control. The cutoff level for rubella was 0.3 ; for cytomegalovirus, 0.2 , and 0,185 for herpes simplex. The seroconversions were considered as the increase of this ratio as related to the determination during the first trimester of pregnancy. $91.3 \%$ of the pregnant women appeared to be positive to rubella, $92.7 \%$ for cytomegalovirus, and $98.1 \%$ of the pregnant women appeared to be positive to HSV. This study underlined the need to take into consideration some important issues concerning these infections within the National Care Program for Pregnant Women.

Key words: rubella, cytomegalovirus, pregnant women, Havana City

En el grupo de las infecciones del síndrome de TORCH encontramos tres agentes virales: la rubéola, el citomegalovirus (CMV) y el herpes simple (VHS), los cuales, en potencia, pueden provocar infecciones que resultan difíciles de diagnosticar de forma clínica por la similitud de signos y síntomas o por presentarse en forma inadvertida.

Correspondencia:

C. Acosta: Centro de Inmunoensayo, Apartado 6653, Ciudad de La Habana, Cuba

iqmonoclo@cie.sld.cu

Recibido: 12/06/00; aceptado: 18/05/01
Cuando un médico se encuentra frente a la necesidad de establecer el diagnóstico de agentes virales en el curso del embarazo tales como el virus de la rubéola, el citomegalovirus o el herpes simple (VHS), se enfrenta a un problema de extrema delicadeza y de enorme importancia. El solo criterio clínico no es suficiente por lo que resulta necesario acudir al diagnóstico serológico.

En estudios realizados para establecer la prevalencia de anticuerpos específicos de la clase IgG para estas entidades virales, se pudo establecer que cerca del $92 \%$ de la población 
femenina comprendida entre los 16 y 40 años presentan anticuerpos (1).

Tanto la rubéola como el citomegalovirus adquiridos en el curso del embarazo pueden causar muerte fetal, aborto espontáneo o el nacimiento de un neonato con graves o mínimas malformaciones o de un neonato sano.

Si la infección materna ocurre en el primer trimestre del embarazo, prácticamente todos los neonatos muestran signos serológicos de una infección intrauterina y la mayoría presenta una o varias anomalías congénitas $(2,3)$.

En el caso de la infección por VHS, la transmisión de la infección al feto o neonato puede ocurrir por tres vías: en el útero, en el parto o durante la lactancia materna. En el útero, la infección por VHS puede ocurrir por vía transplacentaria ascendente (4). Se han informado evidencias de necrosis en la placenta e inclusiones como un signo de una infección transplacentaria. Esta situación puede estar asociada con hidrocefalia en el neonato en el momento del nacimiento y con abortos espontáneos o con una viremia intrauterina. La segunda vía, y la más común, es el paso de las secreciones infectantes maternas durante el parto. Aproximadamente entre el $75 \mathrm{y}$ el $80 \%$ de las infecciones en el neonato son por vía de contacto genital (5). La tercera vía, la postnatal, atribuida fundamentalmente al VHS-1, ocurre básicamente por la aparición de herpes labial en la madre por el estrés del parto, pudiendo contagiar al neonato con la saliva (6).

En este trabajo, consideraremos de especial interés determinar los niveles de anticuerpos IgG específicos para rubéola, citomegalovirus y herpes simple entre embarazadas residentes en el municipio de Marianao en la capital del país, ya que para justificar un programa de prevención y control de una determinada enfermedad es necesario conocer la real magnitud de la entidad en la población y cuáles son los grupos de personas susceptibles o no al agente patógeno en cuestión.

\section{Materiales y métodos}

\section{Muestras}

Se evaluaron 207 muestras pareadas de sueros provenientes de embarazadas sanas que acudieron al control prenatal en la Policlínica 27 de noviembre en el municipio de Marianao en Ciudad de la Habana. A todas las gestantes analizadas se les realizaron las pruebas complementarias rutinarias en la etapa de captación del embarazo como son la determinación de anticuerpos al VIH, la determinación del antígeno de superficie del virus de la hepatitis $B$ y la prueba VDRL. Es importante señalar que el promedio en semanas de la captación del embarazo es inferior a 12 semanas y que la segunda muestra se toma entre las semanas 15 y 19 de gestación para la realización de pruebas de cuantificación de la alfafetoproteína (AFP) y de la gonadatropina coriónica humana (hCG), enmarcadas en el programa de prevención de malformaciones congénitas y riesgo de portar un feto afectado con el síndrome de Down.

El almacenamiento de los sueros se realizó a $-20^{\circ} \mathrm{C}$ durante un tiempo no mayor de dos meses antes de ser procesados en busca de anticuerpos IgG anti-rubéola, anti-CMV y anti-VHS mediante las técnicas UMELISA (ultramicroELISA) $(1,2,7)$. Estos ensayos son ensayos cualitativos de tipo indirecto.

EI UMELISA rubéola emplea como antígeno la cepa española purificada por gradiente de sacarosa y se utiliza solamente la fracción hemaglutinante, y en el caso de los UMELISA CMV y UMELISA VHS, se emplean antígenos semipurificados y los controles celulares donde son cultivados estos agentes virales.

Los sueros, diluidos 1:20, se aplican a las placas de reacción previamente sensibilizadas y al presentar anticuerpos específicos forman un inmunocomplejo que es reconocido por una antiIgG humana cadena g-específica, obtenida en carnero y conjugada con la enzima fosfatasa alcalina.

El revelado de la reacción se realiza con la adición del sustrato fluorigénico de la fosfatasa alcalina (4-metil-umbeliferil-fosfato). La fluorescencia obtenida es proporcional al nivel de anticuerpos presentes. En todos los pasos, el volumen de reactivos empleados es de $10 \mathrm{ml}$. 


\section{Análisis estadístico}

Los parámetros estadísticos se determinaron empleando el Microsoft Excel, versión 7.0.

\section{Resultados}

De los 207 pares de sueros evaluados, el 91,3, 92,7 y el $98,1 \%$ resultaron positivos a la presencia de anticuerpos IgG anti-rubéola, anti-CMV y antiVHS, respectivamente; estos resultados concuerdan con los niveles de prevalencia informados en diferentes países para rubéola y CMV y, en el caso de las infecciones por el VHS, coincide con un estudio realizado previamente en 306 gestantes, el cual dio como resultado que $96,97 \%$ presentaban anticuerpos IgG para el herpes simple $(2,3)$.

En todos los casos, se realizó la determinación de anticuerpos IgG específica en el segundo trimestre del embarazo y se encontraron 2 casos de rubéola con incremento de los niveles de positividad del segundo suero con respecto del primero de 3, 32 y 100 veces; para CMV, 3 casos, con un incremento que osciló entre 8, 17 y 40 veces; para VHS, se obtuvieron 4 casos con un incremento de los niveles de relación del segundo suero respecto del primero que osciló entre 6, 64 y 93 veces. Todos los sueros en los cuales se observó la seroconversión, se evaluaron en paralelo durante un mismo ensayo para garantizar que no existieran variaciones importantes entre pruebas.

Los resultados obtenidos en estos sueros nos indican que nos encontramos en la rama ascendente de la curva de expresión de la evolución de los anticuerpos específicos, lo que sería igual a una primoinfección o reinfección; se obtuvo un $0,97 \%$ de seroconversión para rubéola, $1,44 \%$ para citomegalovirus y un $1,93 \%$ de seroconversión para VHS (cuadros 1,2 y 3 ).

Cuadro 1. Seroconversión de anticuerpos IgG anti-rubéola en embarazadas.

\begin{tabular}{cccc}
\hline $\begin{array}{c}\text { No. } \\
\text { del caso }\end{array}$ & $\begin{array}{c}\text { 1er trimestre } \\
\text { (M/P) }\end{array}$ & $\begin{array}{c}\text { 2do trimestre } \\
\text { (M/P) }\end{array}$ & $\begin{array}{c}\text { Incremento } \\
\text { (veces) }\end{array}$ \\
\hline 92 & 0,01 & 1,00 & 100 \\
421 & 0,25 & 0,83 & 3,32 \\
\hline
\end{tabular}

Nivel de corte: 0,3
Cuadro 2. Seroconversión de anticuerpos IgG anti-CMV en embarazadas.

\begin{tabular}{cccc}
\hline $\begin{array}{c}\text { No. } \\
\text { del caso }\end{array}$ & $\begin{array}{c}\text { 1er trimestre } \\
\text { (M/P) }\end{array}$ & $\begin{array}{c}\text { 2do trimestre } \\
\text { (M/P) }\end{array}$ & $\begin{array}{c}\text { Incremento } \\
\text { (veces) }\end{array}$ \\
\hline 92 & 0,01 & 0,4 & 40 \\
414 & 0,12 & 0,98 & 8,17 \\
479 & 0,04 & 0,84 & 21 \\
\hline
\end{tabular}

Nivel de corte: 0,3

Cuadro 3. Seroconversión de los anticuerpos IgG anti-VHS en embarazadas.

\begin{tabular}{cccc}
\hline $\begin{array}{c}\text { No. } \\
\text { del caso }\end{array}$ & $\begin{array}{c}\text { 1er trimestre } \\
\text { (M/P) }\end{array}$ & $\begin{array}{c}\text { 2do trimestre } \\
\text { (M/P) }\end{array}$ & $\begin{array}{c}\text { Incremento } \\
\text { (veces) }\end{array}$ \\
\hline 92 & 0,02 & 1,86 & 93 \\
430 & 0,28 & 1,86 & 6,6 \\
421 & 0,03 & 0,40 & 46,7 \\
565 & 0,05 & 1,33 & 26,6 \\
\hline
\end{tabular}

Nivel de corte: 0,185

\section{Discusión}

En un estudio realizado para la determinación de la prevalencia de anticuerpos lgG a los agentes del TORCH en población en edad fértil, se obtuvo un nivel de positividad del $86,4 \%$ para rubéola y $92 \%$ para citomegalovirus en mujeres, resultado similar al obtenido en nuestro estudio $(8,9)$. En el caso de las infecciones por VHS, se observó una positividad del $89,2 \%$ para las mujeres con un $4,05 \%$ de presencia de anticuerpos de la clase $\lg \mathrm{M}(3)$.

En los resultados obtenidos pudimos constatar la aparición de un caso en el cual ocurre seroconversión para los tres agentes estudiados (cuadros 1, 2 y 3 ). Además, un segundo suero seroconvirtió para rubéola y VHS. Estos resultados han sido señalados por otros autores, demostrando que en el curso de una infección primaria de citomegalovirus se ha detectado respuesta de tipo anamnésico o de reactividad cruzada y heteroespecífica contra rubéola y VHS. Esto mismo se ha constatado para infecciones primarias con el parvovirus B19 $(10,11)$.

El diagnóstico de una reactivación o de una primoinfección por el virus de la rubéola resulta de singular interés, debido a la posibilidad real de 
que el recién nacido resulte infectado por vía hematógena en presencia de viremia, aunque la transmisión por vía cervical no se puede excluir (12). La infección por el virus de la rubéola en la embarazada puede causar la muerte fetal y el aborto espontáneo, así como la aparición de malformaciones en el recién nacido $(13,14)$.

En el caso de una infección por citomegalovirus, se ha demostrado el paso a través de la placenta en el $1 \%$ de los recién nacidos $(15,16)$. De este $1 \%$, de 10 a $15 \%$ presenta una sintomatología evidente en el momento del nacimiento $(5 \%$, enfermedad clásica de inclusión citomegálica y $5 \%$, manifestaciones atípicas variables). El otro 85 a $90 \%$ no presenta sintomatología evidente en el momento del nacimiento, aunque de 10 a $15 \%$ presentará el retardo mental como secuela tardía.

En las gestantes, el diagnóstico de una reactivación o de una primoinfección por herpes simple resulta de singular interés, debido a la posibilidad real de que el recién nacido resulte infectado por tres vías: intrauterina, a través del contacto con las secreciones vaginales en el momento del parto y postparto y durante la lactancia $(17,18)$. Esto puede conducir a que el recién nacido haga un cuadro de infección visceral o del sistema nervioso central, con un pronóstico sombrío (alta mortalidad y alta frecuencia de secuelas) $(17,19)$.

Se ha descrito que una gestante de alto riesgo para la transmisión vertical de rubéola y citomegalovirus es aquélla que es seronegativa y presenta riesgo de primoinfección o, que siendo seropositiva, puede presentar una reactivación del virus latente. Ante una gestante de alto riesgo, existe consenso en torno a recomendar una valoración clínica, serológica y virológica. En el caso de la rubéola, se sugiere la interrupción del embarazo, si se contrajo la infección durante el primero o segundo trimestre. Para citomagalovirus, en el caso de un diagnóstico confirmado, se sugiere la imposición de un tratamiento antiviral a la madre y al recién nacido. En el caso del VHS, se ha descrito a una gestante de alto riesgo para la transmisión vertical como aquélla que presenta una primoinfección o realiza una reactivación del virus latente. Las pacientes seronegativas y cuyo compañero tiene serología discordante deben ser evaluadas en el curso del embarazo. El riesgo de transmisión al recién nacido es de $50 \%$ en los partos por vía vaginal en mujeres con un episodio herpético primario y de $5 \%$ en infección recurrente; la posibilidad de que los recién nacidos infectados presenten signos clínicos es de un $20 \%(5,17)$.

Ante una gestante de alto riesgo, existe consenso en recomendar una valoración clínica, serológica y virológica en el momento del parto y en decidir, con base en los resultados, si el parto se realiza por vía vaginal o por cesárea.

Diversos autores recomiendan, incluso, un examen serológico para VHS al diagnosticarse el embarazo. Un resultado negativo debe acompañarse de un estudio de la pareja. Si el esposo es seropositivo, debe recomendarse evitar la exposición sin protección en la última mitad del embarazo y hacer un seguimiento serológico trimestral de la gestante para detectar una posible seroconversión como expresión de una primoinfección.

Es importante destacar que en nuestro país (Cuba), toda mujer que presente una seroconversión durante el embarazo es remitida a una consulta especializada para analizar la conducta que se debe seguir durante la gestación.

El trabajo preventivo encaminado a reducir los efectos dañinos que pueden provocar estas infecciones durante el embarazo, debe estar dirigido, principalmente, a aquella parte de la población femenina embarazada que evidencie pruebas serológicas negativas entre 8 y 12 semanas de gestación, precisándose qué medidas profilácticas deben extremarse para limitar las posibilidades de infección primaria. De ahí, la necesidad de que el diagnóstico de anticuerpos específicos se realice tempranamente durante el período de gestación y que continúe el seguimiento durante el embarazo para garantizar la salud de futuro recién nacido.

\section{Agradecimientos}

Los autores agradecen a lleana Baluja Conde por su valiosa ayuda en la confección de este trabajo. 


\section{Referencias}

1. Acosta C, Pérez $X$, Herrera R, Solís RL, López R, Machín $\mathbf{R}$, et al. Evaluación clínica del UMELISARubéola. Congreso Biotecnología-Habana 92, junio 812, 1992.

2. Pérez X, García R, Acosta C, Herrera R, Torrella A, López R. Estado inmune de las embarazadas frente a los agentes del TORCH. I Congreso de Medicina Tropical, 1993.

3. Iorio R, Lombardi A, Grillone R, Ferrazzani A. Prevalenza degli anticorpi di classe IgG e IgM del complesso ToRCH in un campione di soggetti in eta'puberale. The Ligand Quarterly 1992;11:545.

4. Whitly RJ. Herpes simplex viruses. En: Fields BN, Knipe DM, editors. Virology. New York: Raven Press; 1990. p.1843.

5. Prober CG, Sullender WM, Yasukawa LL. Low risk of herpes simplex virus infection in neonates exposed to the virus at the time of vaginal delivery to mothers with recurrent genital herpes simplex virus infection. $N$ Engl J Med 1987;316:240.

6. Light IJ. Postnatal acquisition of herpes simplex virus by the newborn infant: a review of the literature. Pediatrics 1979;63:480.

7. Acosta C, Pérez X, Herrera R, Solis RL, López R, Machín R, et al. Evaluación clínica del UMELISA-VHS; Congreso Biotecnología-Habana 92, junio 8-12, 1992.

8. Revello MG, Gerna G. Ligand Quarterly 1992;11:489.

9. Landini MP, Lazzarotto T. Citomegalovirus. The Ligand Quarterly 1992;11:495.
10. Gerna G, Zannino M, Revello MG, et al. Development and evaluation of a capture ELISA for determination of rubella immunoglobulun $\mathrm{M}$ using monoclonal antibodies, J Clin Microbiol 1987;25:1033.

11. Kurtz JB, Anderson MJ. Cross-reactions in rubella and parvovirus specific $\lg M$ test. Lancet $1985 ; 2: 1356$.

12. Tondury G, Smith DW. Fetal rubella pathology. J Ped 1960;68:867.

13. Miller E, Cradock-Watson JE, Pollock TM. Consequences of confirmed maternal rubella at succesive stages of pregnancy, Lancet 1982:2:781.

14. Grillner L, Forsgren M, Barr B, et al. Outcome of rubella during pregnancy with special reference to the $17^{\text {th }}$ $24^{\text {th }}$ weeks of gestation. Scand J Infect Dis 1983;15:321.

15. Alford CA, Britt WJ. Cytomegalovirus. En: Fields BN, editor. Virology. Seond edition. New York: Raven Press; 1990.

16. Alford CA, et al. Congenital and perinatal cytomegalovirus infections. Rev Infect Dis 1990;12:S745.

17. Whitley RJ. Herpes simplex viruses. En: Fields BN, Knipe DM, editors. Virology. New York: Raven Press; 1990. p. 1843 .

18. Corey L, Adams H, Brown A, et al. Genital herpes simplex virus infections: clinical manifestation, course and complications. Ann Intern Med 1983;98:958.

19. Whitley RJ, Corey L, Arvin A, et al. Changing presentation of neonatal herpes simplex infection. J Infect Dis 1988;158:109. 